\title{
Adapting global shared socio-economic pathways for national and local scenarios
}

\author{
Bob Frame $^{\mathrm{a}, *}$, Judy Lawrence ${ }^{\mathrm{b}}$, Anne-Gaelle Ausseil ${ }^{\mathrm{c}}$, Andy Reisinger ${ }^{\mathrm{d}}$, \\ Adam Daigneault ${ }^{\mathrm{e}}$ \\ ${ }^{a}$ Manaaki Whenua - Landcare Research New Zealand, PO Box 69040, Lincoln 7640, New Zealand \\ ${ }^{\mathrm{b}}$ Climate Change Research Institute, Victoria University of Wellington, Wellington, New Zealand \\ ${ }^{c}$ Manaaki Whenua - Landcare Research New Zealand, 86-90 Lambton Quay, Wellington, New Zealand \\ ${ }^{\mathrm{d}}$ New Zealand Agricultural Greenhouse Gas Research Centre, Private Bag 11008, Palmerston North, New Zealand \\ e School of Forest Resources, University of Maine, Orono, ME 04469, USA
}

\section{A R T I C L E I N F O}

\section{Keywords:}

Scenarios

Socio-economic

Adaptation

Mitigation

Global

National

\begin{abstract}
A B S T R A C T
Socio-economic scenarios enable us to understand the extent to which global-, national- and local-scale societal developments can influence the nature and severity of climate change risks and response options. Shared socio-economic pathways (SSPs) enable a systematic exploration of the challenges to adaptation and mitigation that alternative futures entail. However, SSPs are primarily defined for the global scale. If countries are to test their adaptation and mitigation options for robustness across plausible future socio-economic conditions, then SSPs require country-relevant detail to understand climate change risks at the national and local scales. New Zealand is used to illustrate how nationally relevant socio-economic scenarios, nested within SSPs can be developed to inform national- and local-scale studies of climate change impacts and their implications. Shared policy assumptions were developed, involving a mix of climate-specific and non-climate-specific policies, to demonstrate how international links and global-scale developments are critical locally-local choices may accelerate, reduce or even negate the impact of global trends for extended periods. The typology was then 'tested' by applying it in a local context. The research challenges observed in developing credible, salient and legitimate nationalscale socio-economic scenarios include issues in developing scenarios across a multidisciplinary team. Finally, recommendations for adapting shared climate policy assumptions to produce national and local scenarios, and for assessing the feasibility and effectiveness of climate change adaptation options are presented. These include the need for: guidelines to embed national scenarios in global frameworks; a limit the number of plausible futures; inter-operability of models; an ability to work towards effective multi-disciplinary teams and integrative research; and the opportunity to involve participatory processes where feasible.
\end{abstract}

\section{Introduction}

Risk related to climate change is the product of three interacting drivers: climatic hazards, exposure to those hazards, and vulnerability to those hazards (IPCC, 2014). All three change over time. Much research has focused on understanding and quantifying future global changes in climate-related hazards, and on understanding and modelling the sensitivity of natural and human systems to

\footnotetext{
* Corresponding author.

E-mail address: research@frameworks.nz (B. Frame).
} 
those changes. Much less effort has been invested in understanding how socio-economic trends could alter both exposure and vulnerability to hazards over time, which could have a critical influence on the actual risks from future climate change and the feasibility and effectiveness of adaptation options at a national or local scale.

A global climate scenario toolkit was developed (Ebi et al., 2013; Kriegler et al., 2013; O'Neill et al., 2013; van Vuuren et al., 2013) to provide a typology of alternative futures, and that has enabled systematic exploration of adaptation and mitigation challenges arising from alternative socio-economic futures for different climate scenarios (O'Neill et al., 2017; Riahi et al., 2017).

Several elements constitute the typology of alternative futures. The first element is the representative concentration pathways (RCPs), which describe the global atmospheric radiative forcing associated with varying levels of GHG emissions and concentrations (van Vuuren et al., 2013) up to 2100, and provide input to physical climate models to understand consequent changes in temperature and sea level. Global climate models provide boundary conditions for regional climate modelling, with finer spatial and temporal resolutions and characterization of additional climate variables (such as climate extremes) of relevance to policy, planning and resource management.

The second element is the shared socio-economic pathways (SSPs), which describe future global socio-economic conditions, including associated emissions of GHGs (O’Neill et al., 2013). They outline plausible alternative states of human and natural societies at a macro scale, and include narrative and quantitative elements of socio-ecological systems such as demographic, political, social, cultural, institutional, lifestyle, economic and technological variables and trends. They also include the human impacts on ecosystems and ecosystem services, such as air and water quality, and biodiversity. The global SSPs are designed to be extended to regional and sectoral scenarios.

The architecture and application of SSPs in impact, adaptation and vulnerability studies have mostly been at the global or broad regional scale (e.g., Arnell and Lloyd-Hughes, 2014; Hasegawa et al., 2015; O’Neill et al., 2013). Risks from climate change always reflect the interplay of forces across different scales, but local conditions can influence the severity of climate-related risks and adaptation options. There are only a few examples of studies that build on the SSP architecture and apply it at the regional level (Alfieri et al., 2015; Carey, 2014; Palazzo et al., 2017), the national scale (König et al., 2015; Steininger et al., 2016), or the subnational scale (Absar and Preston, 2015; Nilsson et al., 2017).

SSPs do not themselves contain climate policies, and require the development of additional shared policy assumptions (SPAs) that describe how a world that follows a specific SSP might, in a specific climate change context, adapt to change and reduce emissions to achieve a certain climate outcome prescribed through an RCP. Kriegler et al. (2013) argue that global SPAs should only contain information about climate policies. We argue, however, that national SPAs, especially if they seek to inform understanding of climate change risks and adaptation options, need to contain a mix of climate-specific and non-climate-specific policies to ensure scenarios are credible with stakeholders and salient to the climate change risks individual countries face. This is because national and local choices for managing natural resources and hazards will strongly influence how climate-related risks materialize, and which response options are more or less consistent with existing institutions and governance mechanisms. Such an approach would enable consistency with a country's distinct environmental and land-use governance and institutional architecture. In other words, there are potentially multiple synergies and conflicts arising from the interaction of climate and non-climate policies in a given jurisdiction (e.g., Daigneault et al., 2017a), and these interactions need to be captured in a national-scale scenario to understand the risks and feasible responses.

In addition, the global typology assumes that nations are "mini-worlds" which is unlikely to hold true in many cases and as such the architecture will not reflect the local conditions which can influence the severity of climate-related risks and adaptation options. Recent research has presented methods to 'downscale' global assumptions and estimates, with a primary focus on quantifying metrics that are typically broad and based on a consistent set of inputs and assumptions across countries (Leimbach et al., 2017). Examples include using population, productivity, and capital stock growth to estimate regional per capita GDP (Dellink et al., 2017), or changes in age structure, educational attainment, and economic growth to project national per capita income (Cuaresma, 2017).

Accordingly, this paper develops a set of globally linked, national-scale socio-economic scenarios to 2100 and applies them for illustrative purposes in a New Zealand (NZ) setting to address the consistency between global scenarios of climatic and socioeconomic projections and parallel scenarios for national and local level analysis through nationally specific shared socio-economic pathways (SSP). Achieving such consistency is essential to provide a rigorous context at the national scale that fits into larger global assessments of hazards, exposure and vulnerability to climate risk. The scenarios are intended to be "plausible and often simplified descriptions of how the future may develop, based on a coherent and internally consistent set of assumptions about key driving forces and relationships" (Rounsevell and Metzger, 2010). The challenge is to reflect a country's unique conditions and plausible development choices within a set of global socio-economic development trajectories. Such scenarios will help assess climate-related risks, vulnerabilities and adaptive response options. In principle the scenarios could also help assess mitigation options, though less emphasis is given to greenhouse gas (GHG) emissions, except where they reflected environmental policy changes that also interact with a country's vulnerability to climate change.

Developing national scale scenarios, and within them specific local scenarios, is challenging because no country can be adequately understood as a mini-world. For scenarios to have traction in their local jurisdiction and reflect national governance and cultural traditions, they must have:

- credibility (scientific adequacy of the technical evidence and arguments)

- salience (relevance of the assessment to the needs of decision makers)

- legitimacy (production of information and technology that consider stakeholders' divergent values and beliefs) (Cash et al., 2002) 
National-scale scenarios need, therefore, to employ a nested approach of national and sub-national datasets to reflect global trends as well as the unique national development choices and existing institutional arrangements that may reinforce or work against global trends. Scenarios that have salience and legitimacy with stakeholders have to include non-climate and climate policy elements that reflect perceived or real national issues, such as the economic and social impact of land-use and environmental policy, and the production of GHGs. They should also position domestic climate change policies (both mitigation and adaptation) relative to those embedded at global scales for different SSPs and climate scenarios.

We examine the challenges in nesting country-level socio-economic scenarios within global scenarios (Section 2) to achieve consistency between global scenarios and parallel scenarios at the national and local levels. We then present the New Zealand illustration (Section 3) and show how scenarios were selected to understand vulnerability and adaptation options to climate change at the local scale, outline how these scenarios were populated with quantitative data derived from numerical models supplemented by qualitative proxies, and then explore their application across five local landscapes. Finally, we reflect on the processes and potential gaps (Section 4) then conclude with recommendations to achieve consistency across global, national and local scenarios (Section 4).

\section{Nationally credible, salient and legitimate scenario typology}

\subsection{Overall framework}

While the approach used in this paper builds on the global climate scenario toolkit (Ebi et al., 2013; Kriegler et al., 2013; O'Neill et al., 2013; van Vuuren et al., 2013), it differs from existing approaches that have used this framework to develop national-scale scenarios which rely on either top-down downscaling of global models (Absar and Preston, 2015) or solely on bottom-up participatory processes (Nilsson et al., 2017; Palazzo et al., 2017). This paper by contrast develops nested country-level socio-economic scenarios within global scenarios that can be credible, salient and legitimate within the particular governance and cultural traditions of a country and thus can be applied practically for mitigation and adaptation. The overall process is presented in Fig. 1 .

New Zealand provides a relatively straightforward location to illustrate our approach (see Supplementary Material S1). Its small size, relative geographical isolation, independence of external policy, and strong reliance on trade and migration mean that socioeconomic developments cannot be captured appropriately by simply downscaling global scenarios (Reisinger et al., 2014; van Vuuren et al., 2010). In particular, New Zealand's approaches to the management of water resources, and the weight given to environmental

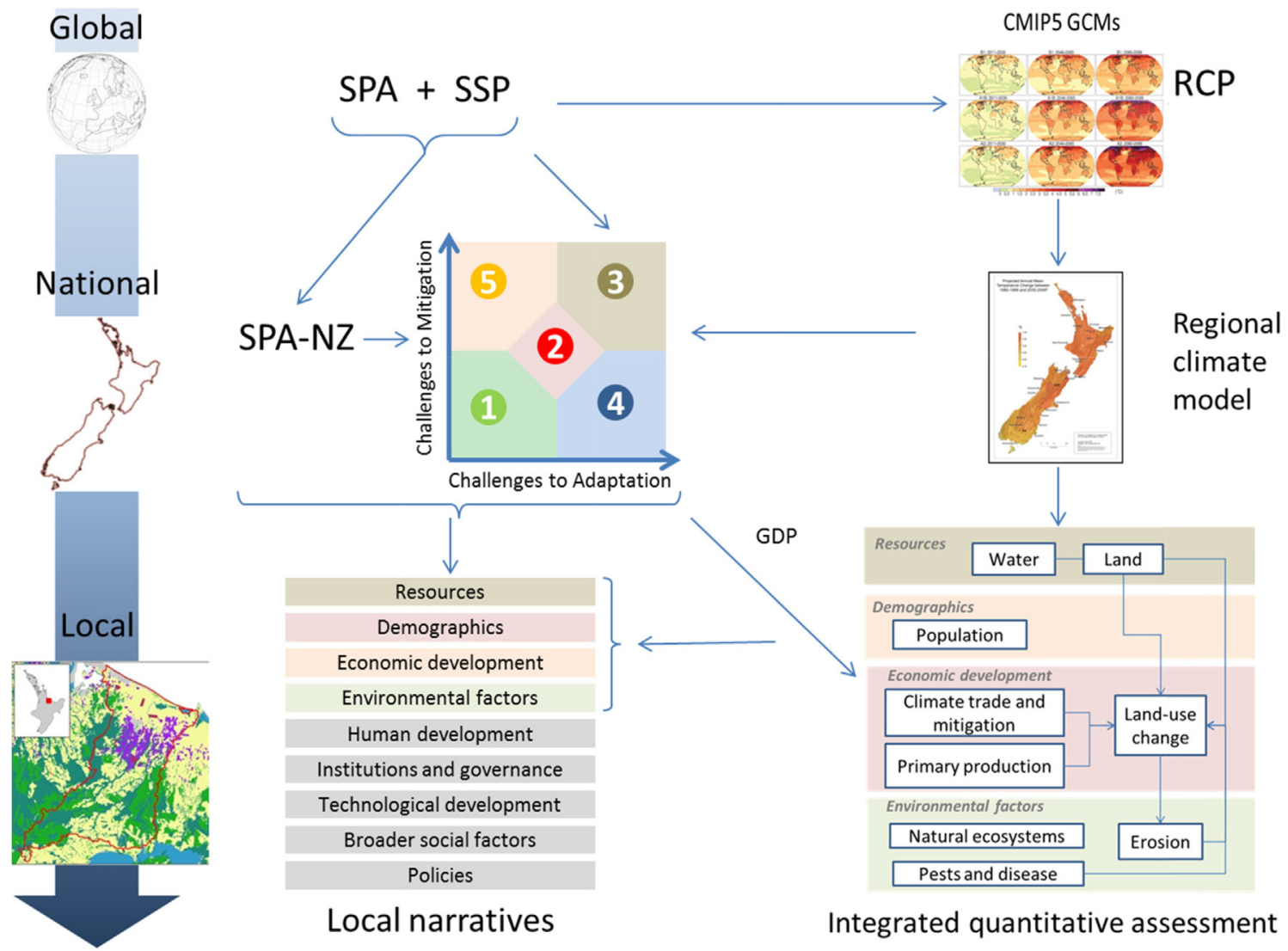

Fig. 1. Schematic representation of nested scenarios from global to national to local. SPA $=$ shared policy assumptions, SSP $=$ shared socio-economic pathways, RCP = representative concentration pathways. 
considerations, could critically influence the impacts of climate-related changes in water resources on society and ecosystems. For local-scale scenarios to be salient, credible and legitimate, such dimensions needed to be specified and justified as part of nationalscale SPAs. This bottom-up element we describe as the shared policy assumptions for NZ (SPANZ), which include both non-climate policies that strongly influence New Zealand's vulnerability and response options to climate-related risks, and potential climate change mitigation and adaptation policies. Together, these policy settings enable New Zealand-specific climate-related risks and response options to diverge from trends that are assumed in global-scale SSPs, even while other aspects (such as international trade and consumer preferences, migration pressures, fossil fuel costs) will be determined by global trends. These policy assumptions comprise a mix of qualitative and quantitative indicator elements and scenario narratives. As such, the SPANZ provide a third axis to the scenario matrix that can be used for assessing climate risks and deciding adaptation options. New Zealand will, in the main, be a future-taker in terms of climate change impacts, but can, within limits, be a future-maker for its own pathway within that global future. Our approach is therefore to initially take the global RCPs and SSPs as given and to map onto those a national set of SPAs based on a modest set of options that reflect alternative choices for NZ within such global developments. That is, the SPANZ will cover a range of NZ responses to climate change in the context of the wider global response.

New Zealand has a long tradition of futures thinking which has increasingly moved towards highly participatory processes (Frame, 2018). This enables stakeholder groups to come together to facilitate scenarios development. In turn, this combines with a very high degree of social connectedness giving a high level of inter-connectedness amongst the research community, policy makers and the business world. This is in part due to New Zealand's small population which gives us far easier access to decision-makers than there is likely to be in Europe or North America. Such access is reflected in research funding being awarded for high degrees of interaction with end-users. Within this context, the New Zealand scenarios shown in this paper were developed with contributions from three stakeholder groups, each comprising multi-disciplinary perspectives that did not necessarily align:

(a) Researchers developed the scenario architecture, drawing on prior studies based on SSPs and comparable work done on regionalscale scenarios elsewhere, including the results of downscaling SSPs to a national level where this was not inconsistent with the SPANZ

(b) Local stakeholders provided feedback on the scenarios in local case studies, helping focus on aspects most relevant to their decision-making challenges, which were often dominated by short- to medium-term perspectives and heavily influenced by topical (non-climate) issues

(c) National influencers provided feedback on key quantitative and qualitative dimensions of the national-scale scenarios over long time frames, including the consistency of the scenario architecture with other national-scale scenario and planning exercises

As researchers we were also invited by the New Zealand Treasury to run a workshop with senior central and local government policy-advisors, key influencers from the business sector and other sectoral interest groups involved in long-term strategy at a national level. This enabled us to 'road-test' the scenarios for logical consistency, their applicability in practice and to stimulate interest in rolling out a national set of consistent scenarios that could be freely accessed and adapted by interested parties. By conducting such a robustness test, combined with the input from the three stakeholder groups, we are confident that the scenarios have credibility, salience and legitimacy to support the climate change research community and the decision making settings at national, regional and local levels. As the scenarios are used, our ongoing climate change adaptive planning research will further test scenario credibility and salience to enable them to be legitimate over the long-term. Using such a co-production model means that the credibility, salience and legitimacy was built into the overall process of the research rather than being separate from that overall process. The main tensions with this process were in the priorities placed on different time-scales, for example, business has a relatively short-term focus, whereas climate change impacts will play out over longer timeframes reflected in the 2100 timeframe used for scenario development, noting however, that 2100 was used to reflect the available downscaled data and will be insufficient a timeframe for ongoing adaptive decision making.

Local stakeholder feedback identified that a critical element was the extent to which New Zealand might follow, lead or lag a global response to climate change, as reflected in SSPs and SPAs. A simple matrix (Table 1) represents NZ's possible positions with regard to adaptation and mitigation. The SPANZ were designed against two axes: domestic approach to mitigation and adaptation relative to SSP/RCP. This was then further split according to the relative position of New Zealand against global efforts (lags behind, consistent or leading), and the level of effort on adaptation. Note that the interpretation of any position depends on the global mitigation response represented by a global SSP/SPA. For example, for RCP2.6, (stringent global mitigation actions) even if New Zealand lags behind, it would still mitigate, but might not apply the global carbon price to agricultural emissions; by contrast, for RCP6.0 and SSP3 (moderate global mitigation) New Zealand might focus only on co-benefits as drivers for mitigation.

\subsection{Scenarios: selection and specification of global contexts}

A manageable number of contrasting policy assumptions were selected to construct a set of plausible national-scale scenarios within the global RCP/SSP architecture, using a combination of quantitative and qualitative elements that reflect socio-economic developments. Six scenarios were developed, comprising combinations of RCPs, SSPs and SPANZ, to provide a broad but plausible range of physical and socio-economic futures.

Although these restrictions removed richness from the scenario landscape, it was preferable to focus on scenarios with more intuitive resonance with stakeholders (Riahi et al., 2017). Such choices were necessarily subjective, even though based on expert opinion and stakeholder engagement. These enabled researchers and stakeholders to explore the extent to which alternative socio- 
Table 1

Shared policy assumptions for New Zealand (SPANZ).

\begin{tabular}{|c|c|c|c|}
\hline \multicolumn{2}{|l|}{ SPANZ } & \multicolumn{2}{|c|}{ Domestic approach to adaptation (relative to SSP/RCP) } \\
\hline & & Incremental and focused on short-term gains & Strategic and transformational \\
\hline $\begin{array}{l}\text { Domestic approach to } \\
\text { mitigation (relative to } \\
\text { SSP/RCP) }\end{array}$ & $\begin{array}{l}\text { Consistent with } \\
\text { global efforts }\end{array}$ & $\begin{array}{l}\text { A } \\
\text { NZ lags behind global efforts to mitigate. } \\
\text { Adaptation is incremental and reactive, influenced } \\
\text { by short-term economic gains and vested interests. } \\
\text { The focus is on near-term costs and minimal } \\
\text { adherence to international expectations. } \\
\text { B } \\
\text { NZ neither leads nor lags behind global efforts to } \\
\text { mitigate. Adaptation is incremental and reactive, } \\
\text { influenced by short-term economic gains and } \\
\text { vested interests. There is a strong focus on } \\
\text { minimizing near-term costs while complying with } \\
\text { international mitigation targets. } \\
\text { C } \\
\text { NZ leads global mitigation through innovation. } \\
\text { Adaptation is incremental and reactive, influenced } \\
\text { by short-term economic gains and vested interests. } \\
\text { Policy is dominated by adaptation as a 'second- } \\
\text { best' response based on strong mitigation that } \\
\text { protects NZ's market access. }\end{array}$ & $\begin{array}{l}\text { D } \\
\text { NZ lags behind global efforts to mitigate. Adaptation is } \\
\text { strategic, with transformational changes to achieve } \\
\text { long-term goals. NZ perceives no meaningful role in } \\
\text { limiting climate change through mitigation but will } \\
\text { focus on securing its long-term viability. } \\
\text { E } \\
\text { NZ neither leads nor lags behind global efforts to } \\
\text { mitigate. Adaptation is strategic, with transformational } \\
\text { changes to achieve long-term goals. Policy is } \\
\text { dominated by compliance with international } \\
\text { expectations, while accepting that long-term prosperity } \\
\text { lies in adaptation. } \\
\text { F } \\
\text { NZ leads global efforts through innovation. Adaptation } \\
\text { is strategic to achieve long-term goals. A policy of } \\
\text { adapting to change is key to NZ's well-being, which } \\
\text { includes adaptation and mitigation to secure its } \\
\text { international reputation and fulfil its moral obligations. }\end{array}$ \\
\hline
\end{tabular}

economic futures will interact with different physical manifestations of climate change.

In developing this scenario set to 2100 , decisions were made whether to:

- explore the full range of climate outcomes (the range covered by the RCPs) but using a narrower range of socio-economic futures, or

- focus on contrasting socio-economic global futures (reflected by different SSPs) but only for selected climate futures, or

- focus on different national choices (SPANZ) within global futures (reflected by different SSPs and SPAs) for a limited range of climate outcomes

Since the scenarios were to test sensitivity to alternative socio-economic futures, the SSP2 'middle of the road' scenario was not used. Some RCP/SSP combinations, such as RCP8.5 with SSP1, or RCP2.6 with SSP3, were not considered plausible (Riahi et al., 2017). For two climate scenarios (RCP4.5 and RCP2.6), two contrasting socio-economic contexts were explored, while upper-end climate outcomes were represented by only one socio-economic scenario each (Fig. 2).

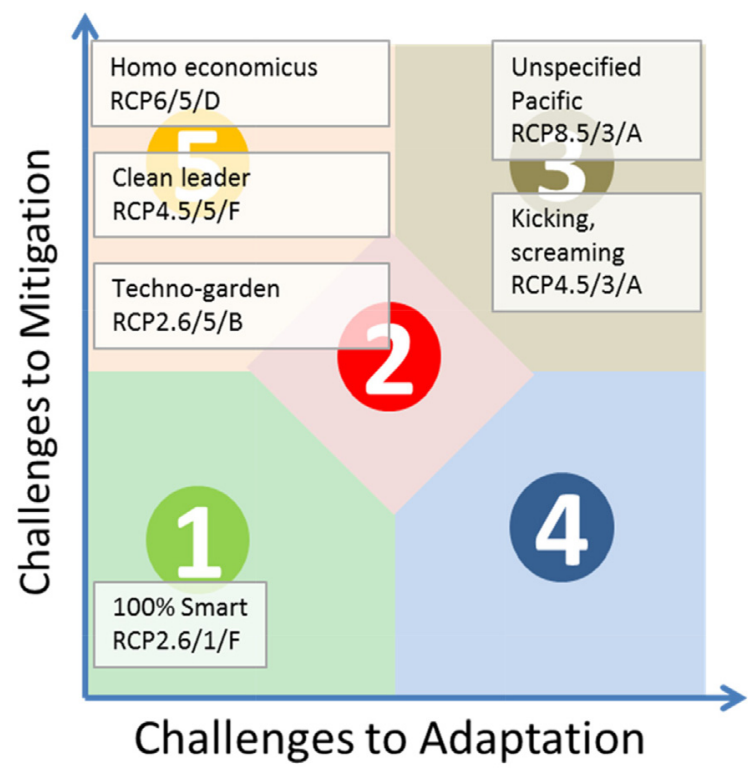

Fig. 2. Global Shared Socio-economic Pathways (SSPs) from O'Neill et al. (2013) and selected New Zealand scenarios (RCP/SSP/SPANZ). 
From the set of six SPANZs that were designed (Table 1), the following four SPANZs were selected to keep the initial set of scenarios manageable:

- A: NZ mitigation lags global policy with incremental, short-term NZ adaptation

- B: NZ mitigation complies with global mitigation and adaptation initiatives through incremental, short-term NZ adaptation

- D: NZ mitigation lags global mitigation policy yet is focussed on strategic, highly transformative adaptation

- F: NZ mitigation leads global policy and is focussed on strategic, highly transformative adaptation

\subsection{Scenarios: quantitative and qualitative data}

Qualitative and quantitative elements are needed for salience. For the quantitative elements, the RCPs were downscaled using NZ climate models that generated climate projections down to a $5 \mathrm{~km}$ grid (Tait et al., 2016b). For the SSP element there was a choice between downscaling the global SSP and SSP/SPA database and model results (www.tntcat.iiasa.ac.at/SspDb; see Riahi et al., 2017) or constructing indicators bottom up that reflected nationally specific SPANZ 'flavours'.

This highlights the issue of overall relevance of the global scenarios to the local scale where the drivers of change are quite different from those used to inform the global SSPs. Other studies that used qualitative bottom-up approaches to develop subnational-scale scenarios (e.g., Birkmann et al., 2015; Nilsson et al., 2017) have struggled to locate such scenarios within the global SSP framework. In developing the NZ case study we could not find information on indicators that were important nationally, yet demonstrably embedded within global-scale developments. For example, most domestic data, such as GDP (Bell et al., 2010), population projections (Statistics New Zealand, 2016), scenarios of domestic transport (MOT, 2014) or energy (BEC, 2015) did not exist in a form that allowed them to be tied to global-scale SSPs/SPAs. Many other elements of the O'Neill et al. (2013) indicator framework to describe SSPs were not able to be systematically addressed in the NZ scenarios study, let alone considered in the context of climate change risks and response options. This situation may be similar to other jurisdictions seeking to develop consistent scenarios. However, local scale scenarios can be nested inside the global SSPs, though they may appear very different due to contextual factors.

Given these challenges, national- and local-scale dimensions were incorporated while ensuring internal consistency and transparent links to the global-scale SSP/SPA framework. First, indicators were selected out of the broader set described by O'Neill et al. (2013) that were necessary to creating consistent narratives with demonstrable implications for climate change risks identified as important to NZ (Reisinger et al., 2014). These include fundamental quantitative drivers such as population (including rural/urban distribution) and GDP as aggregate indicators of a financial response capacity, along with qualitative elements such as:

- attitudes to international trade, including access to global and regional markets

- willingness and ability to occupy niches within such markets (e.g., a 'clean and green' high-value brand), but also susceptibility to trade barriers

- migration policies that influence long-term social values

- technological capacity, both in terms of being a fast adopter and the ability to develop early warning systems and solutions to NZspecific problems.

Apart from such core indicators, which reflected NZ's geographical, and geo-political position and reliance on trade, several specific qualitative factors were critical to ensure the salience of scenarios to decision-making and response options. These were identified through stakeholder workshops and literature reviews. These included approaches to water resource management (including water allocation and attitudes to balancing economic, social and environmental benefits), broader governance of land-based resources (land-use change, water pollution, etc.), and the approach to decision-making on natural hazards (critical to managing risks from river flooding and sea-level rise).

To obtain quantitative indicators, downscaled population and GDP figures from the SSP database, along with an explanatory post hoc narrative were used. A climate trade and mitigation model (CLIMAT-DGE ${ }^{1}$ ) to reproduce the RCP emission trajectories was then calibrated with global SSP/SPA variables, including global carbon prices. This allowed quantification of NZ-specific parameters that materially influenced impact studies or as input to models used to conduct impact studies (Rutledge et al., 2017). For example, CLIMAT-DGE was used to derive global commodity prices that directly influenced productivity, land-use change and NZ's ability to absorb climate-related shocks to its agriculture-based economy via international trade. Considering changes in commodity prices was key to understanding how much climate change-or responses to climate change at the local, national or global level-affected a heavily trade-reliant, primary-sector-based economy.

For domestic GHG emissions and future land use, assumptions about agriculture and forestry carbon pricing were adopted from O'Neill et al (2017) (see Supplementary Material Table S.2). However, NZ has an unusual emissions profile with almost 50\% of emissions from livestock agriculture and no shared land borders with other countries. As a result, even though default scenarios imported the global SPA specifications, sensitivity tests were carried out at national and local scales where NZ mitigation policy might differ in magnitude (because domestic policy choices did not link fully with other emissions trading schemes) or in scope (e.g.,

\footnotetext{
${ }^{1}$ The Climate Mitigation, Adaptation and Trade in Dynamic General Equilibrium (CLIMAT-DGE) model, developed by Landcare Research, is a top-down, dynamic, multi-sectoral and multi-regional computable general equilibrium model that describes the global economy and generation of GHG emissions from energy and nonenergy sectors. CLIMAT-DGE represents a global dynamic economic model with a strong focus on New Zealand as a distinct region (Fernandez and Daigneault, 2016).
} 


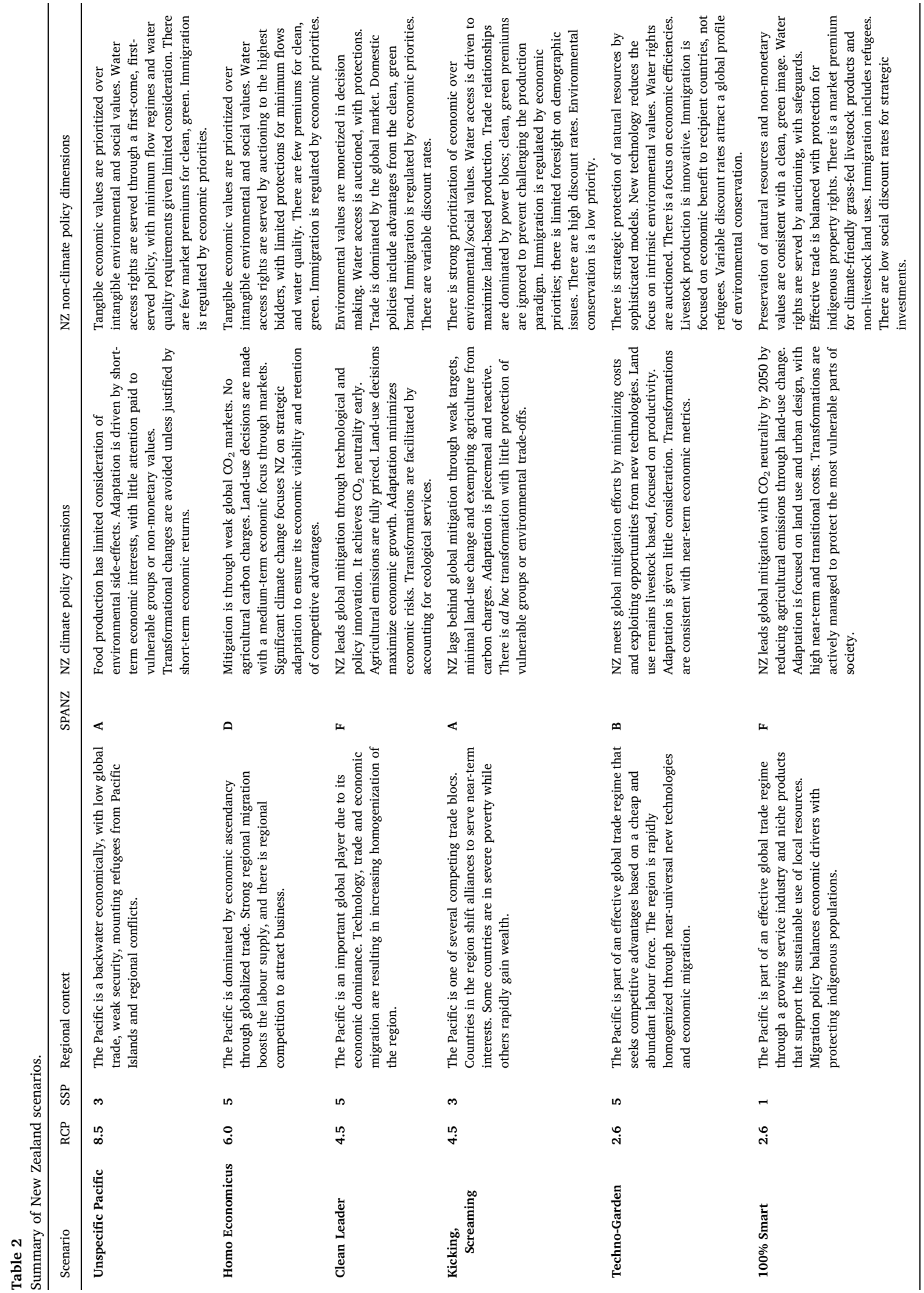




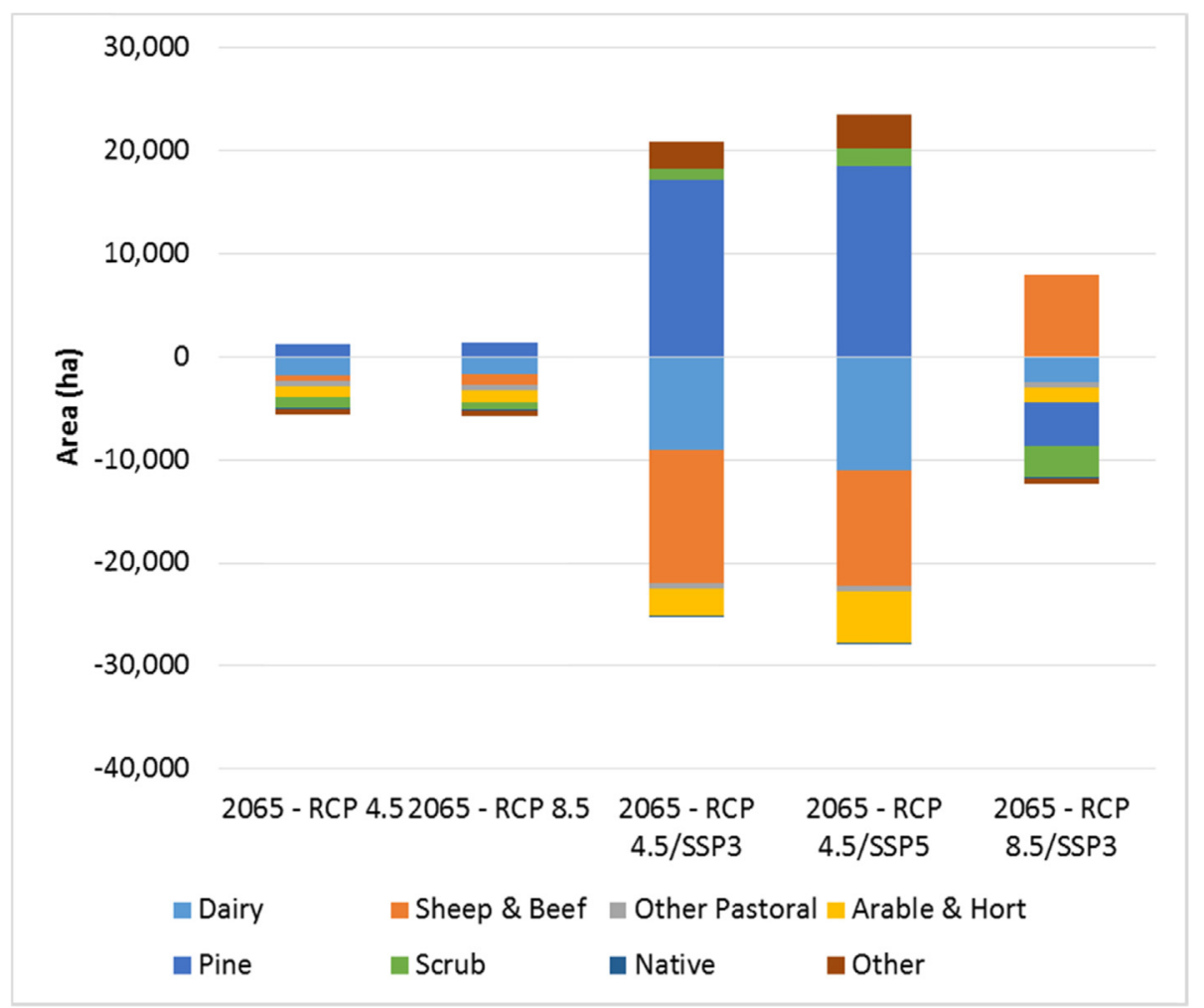

Fig. 3a. Area change results from baseline 2015 to 2065 for scenarios RCP4.5 only, RCP8.5 only and combined scenarios RCP4.5/SSP3/A, RCP4.5/ SSP5/F and RCP8.5/SSP3/A. Changes are greater for the combined scenarios for sheep \& beef, dairy, and pine forest.

during 2008-2012 NZ exempted agricultural emissions from domestic carbon pricing but exposed all other sectors to international carbon prices).

For qualitative aspects, narratives as noted earlier, were constructed in partnership between researchers who ensured internally consistency with the overall scenario logic and the global context; and then 'tested' with decision makers, stakeholders and influencers to ensure legitimacy and salience. For example, within a global SSP3 world (regional rivalry) and a reactive stance to adaptation, water allocation in NZ would more likely follow the (currently dominant) first-come-first-served regime; whereas within a global SSP5 world (economic development) where NZ plays a proactive leadership role, water allocation would more likely be based on trading, coupled with environmental protection. One tension in this process is between the relatively short-term priorities for some decision-makers and the quite long-term perspective (2100) taken by the researchers.

Table 2 summarizes the scenarios and their characteristics. The last two columns summarize key elements of national-scale climate and non-climate policies identified as playing a critical role in understanding the implications of climate change. Such descriptions only illustrate possible narratives.

The quantitative and qualitative indicators were tested as boundary conditions in landscape-based sub-national case-studies. A key challenge was translating qualitative aspects into workable model specifications to allow local-scale case studies to derive quantitative results that reflected qualitative scenario settings.

\section{Applying national scenarios to specific local landscapes}

The national scenario sets to 2100 were tested across a landscape gradient (alpine, upland, lowland, coastal, marine) as detailed in Synthesis Reports (Frame and Reisinger, 2016; Tait et al 2016a). Here the lowland case study is taken to illustrate an assessment of impacts and implications for three of the combined RCP/SSP/SPANZ scenarios ('Unspecific Pacific' (RCP8.5/3/A), 'Clean Leader' (RCP4.5/5/F) and 'Kicking, screaming' (RCP4.5/3/A)). The lowland case study featured freshwater wetland ecosystems and a wide range of primary production, with pressures from fast urban development due to population growth. The changes arising from the quantitative models, coupled with qualitative statements for other elements, are provided elsewhere (Ausseil et al 2016a,b; Supplementary Material S2).

A coupled component modelling approach (Kelly et al., 2013) was adopted to integrate the various models and identify how the components inter-related. To align with the national scenarios, key local scenario assumptions were population change, commodity price changes, carbon pricing, production costs associated with pest management, inadequate winter chilling for fruit production, and impacts from sea-level rise. Notably the effect of change in temperature, precipitation and $\mathrm{CO}_{2}$ concentrations on landowner 


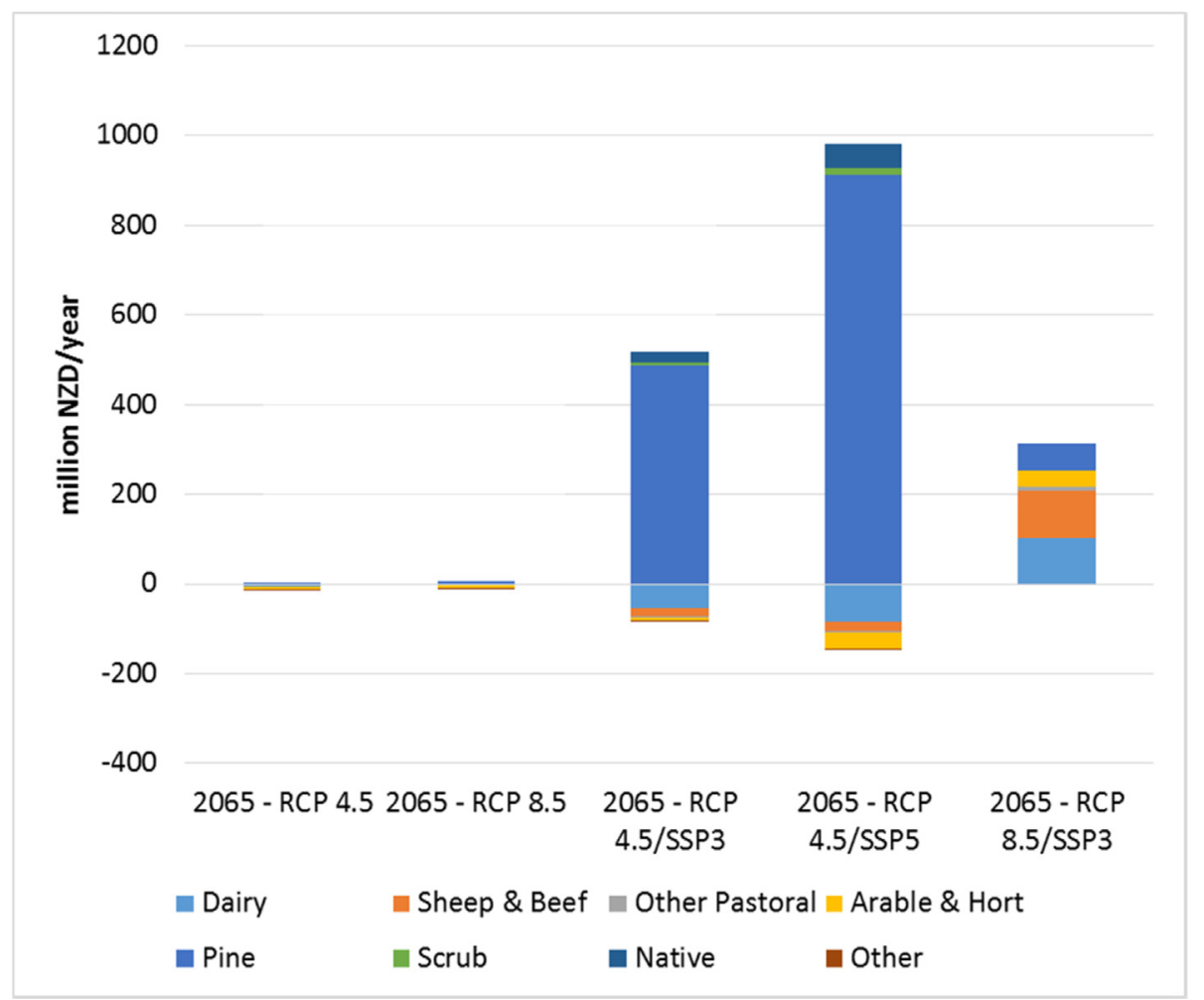

Fig. 3b. Net revenue change for 2065 relative to 2015 (million NZD/yr) for scenarios RCP4.5 only, RCP8.5 only and combined scenarios RCP4.5/ SSP3/A, RCP4.5/SSP5/F and RCP8.5/SSP3/A. Positive changes in net revenue are visible for pine forest in all the combined scenarios but are negative for dairy in RCP4.5/SSP3/A and RCP4.5/SSP5/F. There is a positive net revenue change for sheep \& beef in RCP8.5/SSP3/A.

responses to changes in yield was much smaller than when the RCP and SSP/SPANZ scenarios were combined (Fig. 3, Supplement material S.2, Tables S.1-S.3). In other words, changes in land use were driven more by socio-economic assumptions set in the SSP/ SPANZ scenario, rather than bio-physical projections of climate change.

Moreover changes in land use and net farm revenue by 2065 were largest for 'Clean Leader' (RCP4.5/SSP5/F), followed by 'Kicking, screaming' (RCP4.5/SSP3/A) and 'Unspecific Pacific' (RCP8.5/SSP3/A). This is primarily because 'Unspecific Pacific' (RCP8.5/SSP3/A) assumed no carbon price, limited environmental policy shifts and a relatively stable demand for agricultural commodities, meaning less of a shock to the current economic conditions of the case-study area (Figs. 3a and 3b).

Yet for 'Kicking, screaming' (RCP4.5/SSP3/A), there are large area changes by 2100, as high carbon prices and changes in stakeholder preferences incentivize a shift towards forestry and other low-emitting land uses. The case study also illustrated the importance of qualitative elements: in an 'Unspecific Pacific', international trade could be far more fractured and subject to regional trade blocks and barriers, so the generic assumption that global demand for agricultural commodities remained high may not translate into the stable income stream the local-scale modelling assumed (Figs. 3c and 3d).

The interpretation of the quantitative modelling along with the narrative framework from the national scenario enabled narratives to be created at the local level for the different elements suggested by O'Neill et al. (2013). The example narratives are presented in the Supplement material (Table S.4).

\section{Concluding comments}

We have demonstrated how an extension to the global scenario framework can be used to develop climate change and socioeconomic projections to 2100 for application at national and local levels in a land use decision setting. The process to develop these scenarios was at least as important as content in terms of overall credibility and salience. These reflect the particular aspects that affect mitigation responses and adaptation options at a national level and thus are more likely to be used by decision makers and the results implemented. We turn now to the examine the lessons learned from the process and provide our recommendations on what would improve this overall process and which we hope will develop with further testing globally.

Overall climate change adaptation can be characterized by stakeholders with rival explanations of the problem and different solutions, because of different world views and the complexity of the issue. The process requires an increasingly large number of disciplines to be integrated with many associated challenges (Brown et al., 2015). The can produce tensions between researcherdriven data requirements, which can be led by international and domestic climate knowledge, and country-specific policy-driven needs. The latter may ignore climate-related drivers when developing national-scale projections or decision-making processes. When 


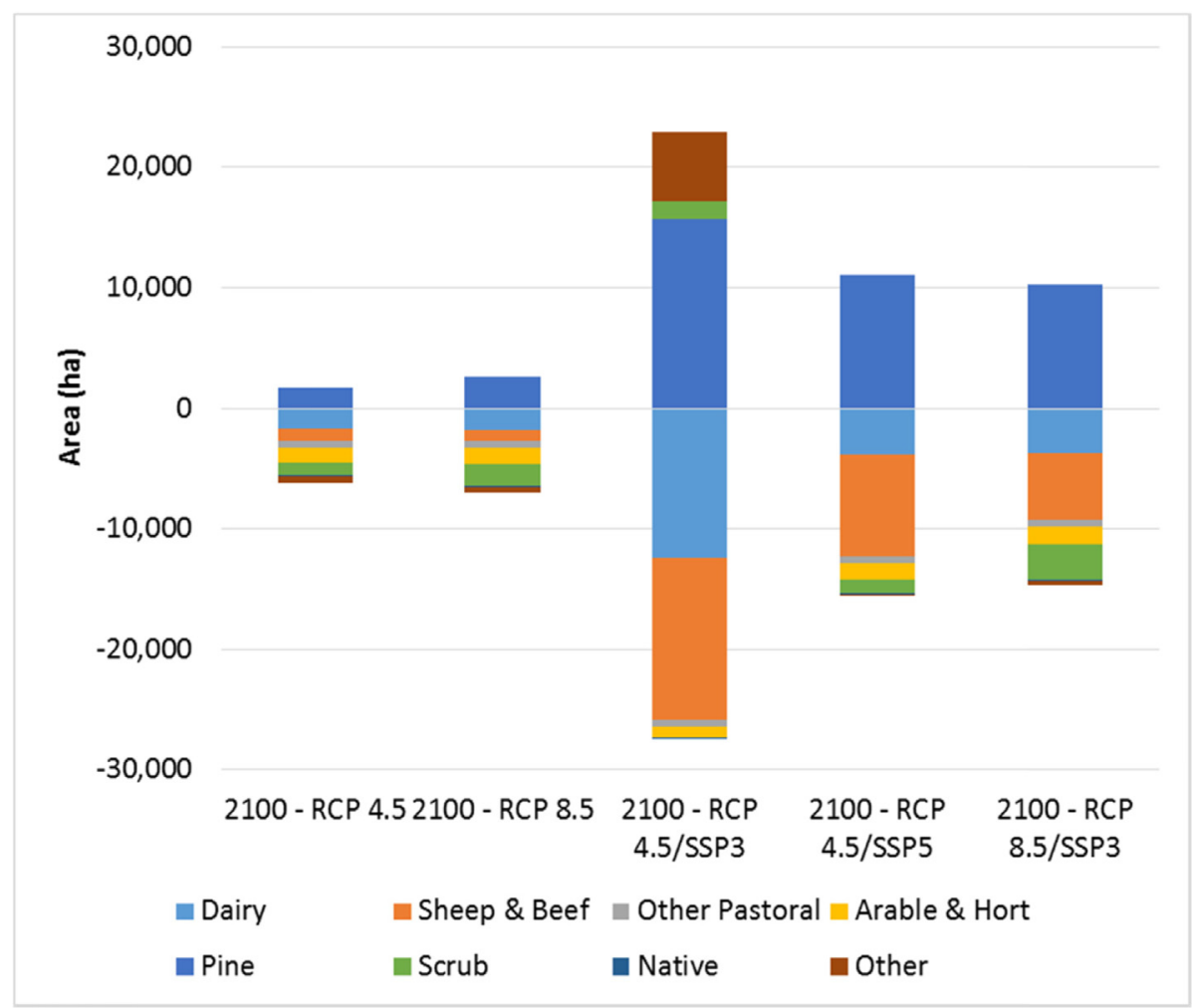

Fig. 3c. Area change results from baseline 2015 to 2100 for scenarios RCP4.5 only, RCP8.5 only and combined scenarios RCP4.5/SSP3/A, RCP4.5/ SSP5/F and RCP8.5/SSP3/A. Changes are greater for the combined scenarios for sheep \& beef, dairy, and pine forest.

included, often only one scenario and a few socio-economic indicators may be used. Maintaining credibility and salience among these multiple tensions was critical, and complex.

As noted in Section 2, development of the New Zealand scenarios required careful facilitation of three stakeholder groups (researchers, local stakeholders and national influencers) each comprising multi-disciplinary perspectives that did not necessarily align. Although New Zealand has a long tradition of futures thinking (Frame, 2018), the process revealed major challenges arising from an absence of long-term national-scale scenarios or experience using scenarios, other than for population and GDP, with little recognition of climate change in any national scenarios and long-term planning. For example, Statistics New Zealand (2016) has developed long-term population scenarios but without reference to climate-related migration pressures; and long-term GDP forecasts are developed by the Treasury (e.g., Bell et al., 2010), but again without reference to climate change or climate policies, or indeed alternative global socio-economic scenarios. Existing sector-specific scenarios (e.g., for transport and energy; BEC, 2015; MOT, 2014) demonstrated minimal congruence methodologically in capturing and understanding relationships, such as those between global policies, commodity prices, carbon prices and energy costs.

Ensuring the indicators were both climate-change-relevant and decision-relevant required a sophisticated level of knowledge and skill to understand enough of each component of the scenario development to enable testing of the credibility, salience and legitimacy of the indicators and narratives.

Based on this application, a number of issues arose requiring further attention. To achieve consistency between global scenarios of climatic and socio-economic projections and parallel scenarios at national or local levels, it is recommended to:

Establish guidelines for embedding national scenarios in global frameworks. Given that national scenarios are not downscaled versions of global RCP/SSP combinations, the processes used in their development and the implications of similar scenarios in different jurisdictions need to be understood and documented. This would enable more specific insights into climate change mitigation and adaptation. It would also reduce the numbers of case studies starting from scratch and, in turn, inform a more rigorous global architecture. A generic national scenarios architecture into which sector-specific scenarios could be included would require agreed processes that conceptualize acceptable trade-offs between complexity and comprehensiveness.

Limit the number of plausible futures. The number of possible futures increases several-fold if national-scale development choices are not just downscaled versions of global-scale SSPs. For any SSP a country could lead or lag global climate policies, or try to remain entirely outside for some period, and non-climate policy choices could influence the impacts and implications of climate change. Trying to capture such diverse national-scale outcomes would soon become unmanageable. While potentially useful for probabilistic approaches, generating multiple, diverse combinations is unwieldy for exploring implications for policy making. If we accept that many national efforts will be constrained by available research resources and by likely research budgets, then guidelines are needed 


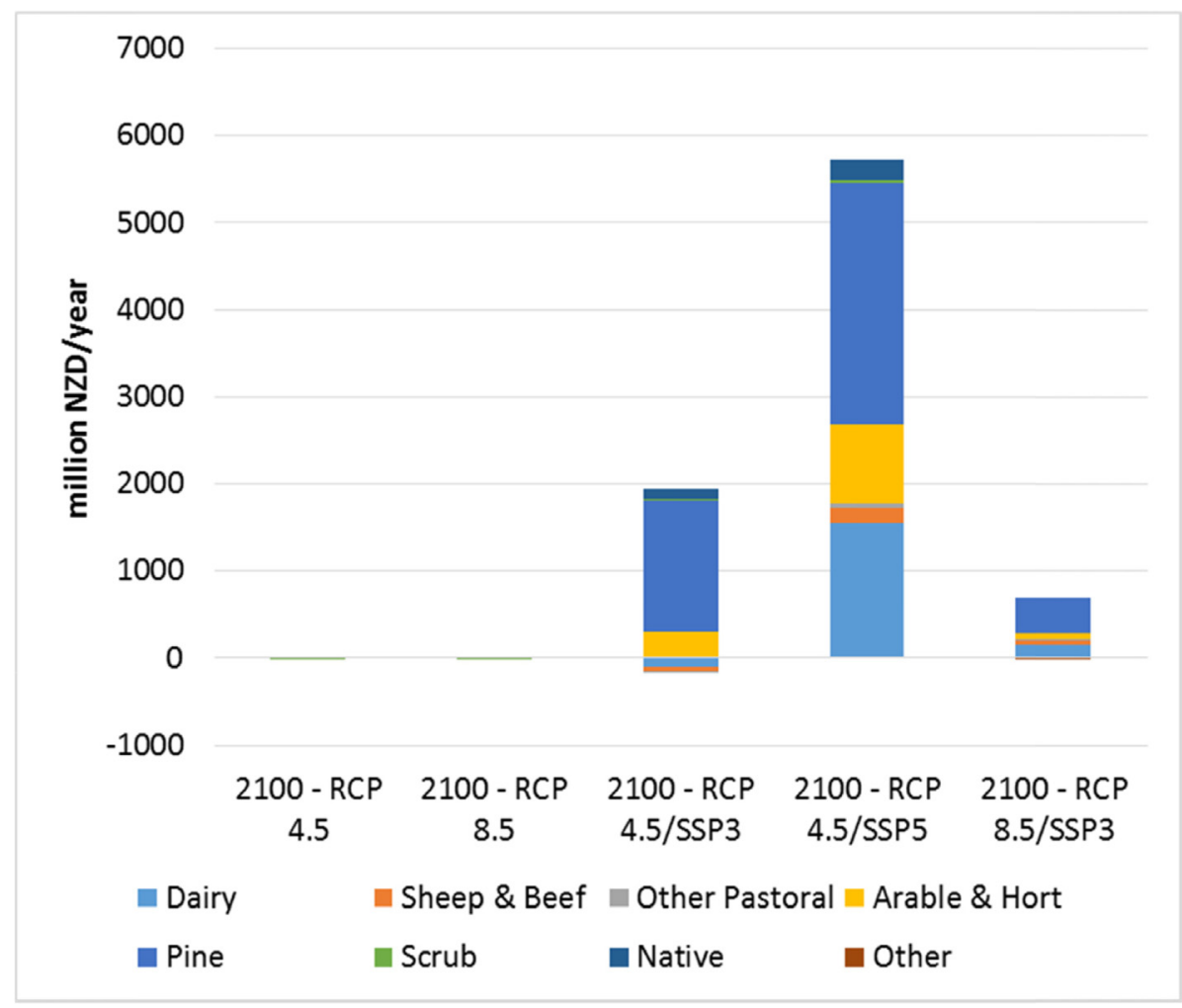

Fig. 3d. Net revenue change for 2100 relative to 2015 (million NZD/yr) for scenarios RCP4.5 only, RCP8.5 only and combined scenarios RCP4.5/ SSP3/A, RCP4.5/SSP5/F and RCP8.5/SSP3/A. Changes in net revenue are visible for pine forest mainly for RCP4.5/SSP3/A and RCP4.5/SSP5/F, and for dairy and arable in RCP4.5/SSP5.

for a manageable number of possible futures that are not just downscaled versions of global-scale SSPs. In turn, the opportunity to read across multiple national scenarios can support policy-makers in decision-making processes.

Strive for inter-operability. Effective production of meaningful local scenarios requires careful integration of modelling using:

- narratives for RCP/SSP combinations from the SSP database at national and local levels

- national-scale SPA narratives nested inside regional RCP/SSP combinations

- documented inter-operability of national models

- documented best practice, especially as it relates to non-quantitative data

- documented integration of bottom-up participatory processes and top-down modelling

All of these issues are made more complex when national and local data for indicator sets used at the global level are not available nationally. Progress towards inter-operability is unlikely to be straightforward.

Work towards effective multi-disciplinary teams and integrative research. Transaction costs are high for biophysical modellers working with economists and other social researchers in a multi-disciplinary team to build scenarios that combine qualitative and qualitative elements. It requires frequent interactions, careful facilitation, and the skill to address frequent challenges. These challenges include:

- availability of data sets at the local level, as used in global scenarios, or an ability to create proxies or qualitative data for the most relevant parameters

- accommodating world views across multiple top-down and bottom-up approaches

- experience of integrated research and co-production of knowledge among researchers and with stakeholders

The need to accommodate adaptive learning into research practice is essential and requires researchers with both depth in a subject and breadth across disciplines (Brown et al., 2015). Most researchers are open to accommodating alternative viewpoints, but there is a tendency to privilege depth over breadth. Similarly, stakeholders may see specific implications as having greater currency than precision of data and methodological rigour. There may also be highly variable data sources covering multiple societal issues. The process used to develop the scenarios must accommodate decision processes taking place in the context of deep uncertainty.

Take a participatory turn. Bottom-up participatory processes that identify key local factors are critical to the overall process. They ensure that local actors have agency in issues they believe are important (Tschakert et al., 2017), not just those dictated by global 
models. Achieving consensus can slow delivery of a final product but is more likely to ensure traction for the scenarios. For example, Nilsson et al. (2017) have used highly interactive workshops involving local and regional participants, including planners, public servants, and representatives from business sectors and NGOs. By looking out one or two generations at local challenges and future changes, participants were able to identify local drivers and build relevant scenarios that differed markedly both within the region and from the global scenarios.

While the task of creating downscaled global scenarios that are meaningful in local situations is challenging for governance actors and communities, the benefits of an accepted architecture that is consistently informed by global modelling as well as local participatory processes are enormous. Nationally credible and salient scenarios enable mitigation and adaptation policies and options to be explored across plausible futures, trust to be built, values to be understood and policies to be more robust under changing climate conditions. To build the architecture at the national and local levels will require not just better coordination within the research community across climate and social sciences, but also a wider acceptance of multiple methodologies and accommodation of qualitative data in decision making processes.

\section{Acknowledgements}

All authors were funded by New Zealand Ministry of Business, Innovation and Employment (MBIE) Contract C01X1225 Climatic conditions to 2100 and assessed impacts and implications for New Zealand's environment, economy and society. Bob Frame, Anne-Gaelle Ausseil and Adam Daigneault were funded to write this paper through Manaaki Whenua - Landcare Research Strategic Science Investment Funds. JL was also funded through MBIE Contract CO1X1412 Deep South National Science Challenge Decision-making Tools and Measures. The input of a range of advisors at national and local levels while 'testing' the scenario typology is acknowledged as are the two anonymous reviewers.

\section{Appendix A. Supplementary data}

Supplementary data associated with this article can be found, in the online version, at https://doi.org/10.1016/j.crm.2018.05. 001.

\section{References}

Absar, S.M., Preston, B.L., 2015. Extending the shared socioeconomic pathways for sub-national impacts, adaptation, and vulnerability studies. Global Environ. Change 33, 83-96.

Alfieri, L., Feyen, L., Dottori, F., Bianchi, A., 2015. Ensemble flood risk assessment in Europe under high end climate scenarios. Global Environ. Change 35, 199-212. Arnell, N.W., Lloyd-Hughes, B., 2014. The global-scale impacts of climate change on water resources and flooding under new climate and socio-economic scenarios. Clim. Change 122, 127-140.

Ausseil, A.G., Bodmin, K., Daigneault, A., Teixeira, E., Keller, L., Kirschbaum, M., Timar, L., Dunningham, A., Stephens, S., Cameron, M., et al., 2016a. Climate change impacts and implications: an integrated assessment in a lowland environment of New Zealand. In: International Environmental Modelling and Software Society 8th International Congress on Environmental Modelling and Software, Toulouse, France. Available from: http://www.iemss.org/society/index.php/iemss-2016proceedings.

Ausseil, A.G., Bodmin, K., Daigneault, A., Teixeira, E., Keller, L., Kirschbaum, M., Timar, L., Dunningham, A., Zammit, C., Stephens, S., et al., 2016b. Climate change impacts and implications: an integrated assessment in the lowland case-study. Synthesis Report RA2. In: Climate Change Impacts and Implications for New Zealand to 2100. Available from: http://ccii.org.nz.

BEC, 2015. In: New Zealand Energy Scenarios. Business NZ Energy Council, Wellington, pp. 108.

Bell, M., Blick, G., Parkyn, O., Rodway, P., Vowles, P., 2010. Challenges and choices: modelling New Zealand's long-term fiscal position. Working Paper 10/01, New Zealand Treasury, Wellington, New Zealand.

Birkmann, J., Cutter, S.L., Rothman, D.S., Welle, T., Garschagen, M., van Ruijven, B., O’Neill, B., Preston, B.L., Kienberger, S., Cardona, O.D., et al., 2015. Scenarios for vulnerability: opportunities and constraints in the context of climate change and disaster risk. Clim. Change 133, 53-68.

Brown, R.R., Deletic, A., Wong, T.H.F., 2015. Interdisciplinarity: how to catalyse collaboration. Nature 525, 315-317.

Carey, C., 2014. The CCAFS Regional Scenarios Programme: External Evaluation Report on Progress Towards Programme Outcomes. CGIAR Research Program on Climate Change, Agriculture and Food Security (CCAFS), Copenhagen, Denmark.

Cash, D.W., Clark, F.A., Dickson, N., Eckley, N., Jäger, J., 2002. Salience, credibility, legitimacy and boundaries: linking research, assessment and decision making. In: RWP02-046. Faculty Research Working Paper Series. Harvard University, John F Kennedy School of Government, Cambridge, MA.

Cuaresma, J.C., 2017. Income projections for climate change research: a framework based on human capital dynamics. Global Environ. Change 42, $226-236$.

Daigneault, A., Elliott, S., Greenhalgh, S., Kerr, S., Lou, E., Murphy, L., Timar, L., Wadhwa, S., 2017a. Modelling the potential impact of New Zealand's freshwater reforms on land-based greenhouse gas emissions. In: Motu Working Paper 17-10. Motu Economic and Public Policy Research, Wellington, New Zealand.

Dellink, R., Chateau, J., Lanzi, E., Magné, B., 2017. Long-term economic growth projections in the Shared Socioeconomic Pathways. Global Environ. Change 42, 200-214.

Ebi, K., Hallegatte, S., Kram, T., Arnell, N., Carter, T., Edmonds, J., Kriegler, E., Mathur, R., O’Neill, B., Riahi, K., Winkler, H., Vuuren, D., Zwickel, T., 2013. A new scenario framework for climate change research: background, process, and future directions. Clim. Change 363-372. http://dx.doi.org/10.1007/s10584-0130912-3.

Fernandez, M., Daigneault, A., 2016. The Paris Agreement and its impact on cattle and food sectors of New Zealand. New Zeal J. Agric. Res. 59, 436-443.

Frame, B., 2018. New Zealand: new futures, new thinking. Futures. http://dx.doi.org/10.1016/j.futures.2018.04.005.

Frame, B., Reisinger, A., 2016. Climate change impacts and implications: exploring options for New Zealand under different global climates. Synthesis Report RA5. In: Climate Change Impacts and Implications for New Zealand to 2100. Available from: http://ccii.org.nz.

Hasegawa, T., Fujimori, S., Takahashi, K., Masui, T., 2015. Scenarios for the risk of hunger in the twenty-first century using shared socioeconomic pathways. Environ. Res. Lett. 10, 014010.

IPCC, 2014. Climate change 2014: impacts, adaptation, and vulnerability. Part A: global and sectoral aspects. In: Contribution of Working Group II to the Fifth Assessment Report of the Intergovernmental Panel on Climate Change. Cambridge University Press, Cambridge, UK.

Kelly, R.A., Jakeman, A.J., Barreteau, O., Borsuk, M.E., ElSawah, S., Hamilton, S.H., Henriksen, H.J., Kuikka, S., Maier, H.R., Rizzoli, A.E., van Delden, H., Voinov, A.A., 2013. Selecting among five common modelling approaches for integrated environmental assessment and management. Environ. Model. Software 47, $159-181$. 
König, M., Loibl, W., Haas, W., Kranzl, L., 2015. Shared-socio-economic pathways. In: Steininger, W.K., König, M., Bednar-Friedl, B., Kranzl, L., Loibl, W., Prettenthaler, F. (Eds.), Economic Evaluation of Climate Change Impacts: Development of a Cross-sectoral Framework and Results for Austria. Springer International Publishing, Cham, Switzerland, pp. 75-99.

Kriegler, E., Edmonds, J., Hallegatte, S., Ebi, K., Kram, T., Riahi, K., Winkler, H., van Vuuren, D., 2013. A new scenario framework for climate change research: the concept of shared climate policy assumptions. Clim. Change 122, 401-414.

Leimbach, M., Kriegler, E., Roming, N., Schwanitz, J., 2017. Future growth patterns of world regions-a GDP scenario approach. Global Environ. Change 42, 215-225. MOT (Ministry of Transport), 2014. Future Demand. Ministry of Transport, Wellington.

Nilsson, A.E., Bay-Larsen, I., Carlsen, H., van Oort, B., Maiken, B., Jylhä, K., Klyuchnikovaf, E., Masloboevf, V., van der Watt, L., 2017. Towards extended shared socioeconomic pathways: a combined participatory bottom-up and top-down methodology with results from the Barents region. Global Environ. Change 45, $124-132$.

O’Neill, B.C., Kriegler, E., Ebi, K.L., Kemp-Benedict, E., Riahi, K., Rothman, D.S., van Ruijven, B.J., van Vuuren, D.P., Birkmann, J., Kok, K., et al., 2017. The roads ahead: narratives for shared socioeconomic pathways describing world futures in the 21st century. Global Environ. Change 42, 169-180.

O’Neill, B., Kriegler, E., Riahi, K., Ebi, K., Hallegatte, S., Carter, T., Mathur, R., van Vuuren, D., 2013. A new scenario framework for climate change research: the concept of shared socioeconomic pathways. Clim. Change 122, 387-400.

Palazzo, A., Vervoort, J.M., D’Croz, D.M., Rutting, L., Havlíka, P., Islam, S., Bayala, J., Kadi, H.K., Thornton, P., Zougmore, R.B., 2017. Linking regional stakeholder scenarios and shared socioeconomic pathways: quantified West African food and climate futures in a global context. Global Environ. Change 45, 227-242. http:// dx.doi.org/10.1016/j.gloenvcha.2016.12.002.

Reisinger, A., Kitching, R.L., Chiew, F., Hughes, L., Newton, P.C.D., Schuster, S.S., Tait, A., Whetton, P., 2014. Australasia. Climate Change 2014: impacts, adaptation, and vulnerability. Part B: regional aspects. In: Contribution of Working Group II to the Fifth Assessment Report of the Intergovernmental Panel on Climate Change. Cambridge University Press, Cambridge, UK.

Riahi, K., van Vuuren, D.P., Kriegler, E., Edmonds, J., O’Neill, B.C., Fujimori, S., Bauer, N., Calvin, K., Dellink, R., Fricko, O., et al., 2017. The shared socioeconomic pathways and their energy, land use, and greenhouse gas emissions implications: an overview. Global Environ. Change 42, 148-152.

Rounsevell, M.D.A., Metzger, M.J., 2010. Developing qualitative scenario storylines for environmental change assessment. Wiley Interdiscip. Rev. Clim. Change 1, 606-619.

Rutledge, D., Ausseil, A.G., Baisden, T., Bodeker, G., Booker, D., Cameron, M., Collins, D., Daigneault, A., Fernandez, M., Frame, B., et al., 2017. Climate change Impacts and implications for New Zealand to 2100: identifying feedbacks, understanding cumulative impacts and recognising limits: a national integrated assessment. Available from: http://ccii.org.nz/wp-content/uploads/2017/07/RA3-Synthesis-report.pdf.

Statistics New Zealand, 2016. National Population Projections: 2016(base)-2068. Statistics New Zealand, Wellington.

Steininger, K.W., Bednar-Friedl, B., Formayer, H., König, M., 2016. Consistent economic cross-sectoral climate change impact scenario analysis: method and application to Austria. Clim. Serv. 1, 39-52.

Tschakert, P., Barnett, J., Ellis, N., Lawrence, C., Tuana, N., New, M., Elrick-Barr, C., Pandit, R., Pannell, D., 2017. Climate change and loss, as if people mattered: values, places, and experiences. Wiley Interdiscip. Rev. Clim. Change 8 e476-n/a.

Tait, A., Sood, A., Mullan, B., Stuart, S., Bodeker, G., Kremser, S., Lewis, J., 2016a. updated climate change projections for New Zealand for use in impact studies. Synthesis Report RA1. Climate Changes, Impacts and Implications (CCII) for New Zealand to 2100. Wellington, New Zealand. Available from: http://ccii.org.nz/ wp-content/uploads/2016/10/RA1-Synthesis-report.pdf.

Tait, A., Rutledge, D.T., Frame, B., Frame, D., Lawrence, J., McBride, G., Overton, J., Reisinger, A., 2016b. Climate changes, impacts and implications for New Zealand to 2100. Synthesis Report: Overall CCII project. Available from: http://ccii.org.nz/wp-content/uploads/2017/07/Overall-CCII-Project-synthesis-report1.pdf.

van Vuuren, D., Kriegler, E., O’Neill, B., Ebi, K., Riahi, K., Carter, T., Edmonds, J., Hallegatte, S., Kram, T., Mathur, R., et al., 2013. A new scenario framework for climate change research: scenario matrix architecture. Clim. Change 122, 373-386.

van Vuuren, D.P., Smith, S.J., Riahi, K., 2010. Downscaling socioeconomic and emissions scenarios for global environmental change research: a review. Wiley Interdiscip. Rev. Clim. Change 1, 393-404. 